\title{
Penentuan Nilai Faktor Mesin Pesawat Sinar-X Radiografi Digital Merek Shimadzu di RSUD Dr. Kanujoso Djatiwibowo Balikpapan
}

\author{
Mambaul Fitriyana $^{1^{*}}$, Suhadi Muliyono ${ }^{1,2}$, Kadek Subagiada ${ }^{1,2}$ \\ ${ }^{1}$ Program Studi Fisika, Universitas Mulawarman, Samarinda, Indonesia \\ ${ }^{2}$ Laboratorium Fisika Dasar, Universitas Mulawarman, Samarinda, Indonesia \\ *E-mail korespondensi: mambaulfitriyana@gmail.com
}

\begin{abstract}
The research on the determining machine factor $(\mathrm{k})$ of Shimadzu digital radiograph X-ray machine have been done at the RSUD Dr. Kanujoso Djatiwibowo Balikpapan. Machine factor should be required in the calculation of radiation exposure which produced by the $\mathrm{X}$-ray machine. Measurement data that have been used as independent variables were current-time, focus distance to the detector and tube voltage variations of $80 \mathrm{kV}$ to 100 $\mathrm{kV}$, while the dependent variable was the $\mathrm{S}$ value. Determination of the $\mathrm{k}$ value was conducted by weighted linear regression between $\mathrm{V}^{2}$ and $\frac{200}{S}$ using the results of research by Seibert and Morin (2011) for the condition of calibrated X-ray machine. Thus, the reseach has obtained the machine factor of the Shimadzu digital radiograph X-ray machine at the RSUD Dr. Kanujoso Djatiwibowo Balikpapan of $k=(0,1360 \pm$ $0,0124) \frac{m R c m^{2}}{k V^{2} m A s}$.
\end{abstract}

Key Words: Machine Factor, S Value, and X-ray machine

\section{PENDAHULUAN}

Radiasi merupakan elemen penting dalam kehidupan manusia, baik dari segi manfaatnya maupun dari segi bahayanya terhadap kesehatan manusia. Radiasi adalah pancaran energi dalam bentuk sinar alfa, beta, gamma dan partikel-partikel elementer lainnya atau gelombang elektromagnetik seperti sinar-X, sinar ultraviolet, inframerah dan lain-lain [7]. Salah satu manfaat radiasi adalah untuk diagnosis dan terapi pada tubuh manusia tanpa harus melakukan operasi bedah terlebih dahulu [6].

Pengukuran atau perhitungan dosis radiasi sangat penting baik pada saat diagnosis maupun terapi. Terdapat dua besaran dosis radiasi yang penting berkaitan dengan proses diagnosis dan terapi yaitu paparan radiasi dan dosis serap. Besaran-besaran tersebut berkaitan dengan faktor-faktor eksposi (tegangan tabung, arus tabung, waktu paparan dan jarak paparan) dan nilai faktor mesin pada pesawat sinar-X yang dipergunakan. Umumnya nilai faktor-faktor eksposi telah ditentukan baik langsung (muncul pada alat) maupun tak langsung (pengukuran). Sedangkan nilai faktor mesin pada pesawat sinar-X umumnya belum diketahui.

Halaman | 29 
Jenis pesawat sinar-X yang digunakan pada penelitian ini adalah pesawat sinar-X radiografi digital merek Shimadzu di Instalasi Radiologi RSUD Dr. Kanujoso Djatiwibowo Balikpapan. Sebelumnya telah dilakukan penelitian tentang penentuan nilai faktor mesin pesawat sinar-X merek Siemens yaitu pada Ayad (2001) yang dari penelitian tersebut nilai faktor mesin memiliki rentang dari $5 \frac{\mathrm{mRcm}^{2}}{\mathrm{kV}^{2} \mathrm{mAs}}$ sampai $30 \frac{\mathrm{mRcm}^{2}}{\mathrm{kV}^{2} \mathrm{mAs}}$. Hasil penelitian yang lain yakni Lestari (2018) yang mendapatkan bahwa nilai faktor mesin pesawat sinar-X merek Philip berkisar antara $0,128570 \frac{\mathrm{mRcm}}{\mathrm{kV}^{2} \mathrm{mAs}}$ sampai dengan $0,278752 \frac{\mathrm{mRcm}}{\mathrm{kV}^{2} \mathrm{mAs}}$. Oleh karena itu kali ini dilakukan penelitian untuk menentukan nilai faktor mesin (machine factor value) pada pesawat sinar-X yang berbeda yaitu merek Shimadzu.

\section{TINJAUAN PUSTAKA}

Paparan radiasi adalah kemampuan sinar-X untuk menimbulkan ionisasi dan digunakan untuk mendeskripsikan sifat emisi sinar-X dari sebuah sumber radiasi. Paparan merupakan besaran untuk menyatakan intensitas sinar- $X$ yang dapat menghasilkan ionisasi di udara dalam jumlah tertentu. Berdasarkan definisi tersebut, maka paparan (E) dapat dirumuskan sebagai [1]:

$$
\mathrm{E}=\frac{d Q}{d m}
$$

dengan dQ adalah jumlah muatan elektron yang timbul sebagai akibat interaksi antara foton dengan atom-atom udara dalam volume udara bermassa $\mathrm{dm}$. Paparan mempunyai satuan coulomb per kilogram-udara $\left(\mathrm{C}_{\mathrm{kg}} \mathrm{kg}^{-1}\right)$ dan diberi nama khusus roentgen disingkat R. Satu roentgen didefinisikan sebagai intensitas sinar- $X$ yang dapat menghasilkan ionisasi di udara sebanyak $1,61 \times 10^{15}$ pasangan ion per kilogram udara. Karena 1 ion bermuatan listrik $1,60 \times 10^{-19} \mathrm{C}$, maka:

$$
1 \mathrm{Ckg}^{-1}=\left(2,58 \times 10^{-4}\right)^{-1} \mathrm{R}=38,76 \times 10^{2} \mathrm{R} .
$$

Paparan radiasi berkaitan dengan faktor-faktor eksposi yaitu [4]:

$$
\mathrm{E}=\frac{k V^{2} i t}{d^{2}}
$$

dengan $\mathrm{E}$ adalah paparan sinar-X pada permukaan objek dalam $\mathrm{mR}, \mathrm{V}$ adalah tegangan tabung dalam $\mathrm{kV}$, i merupakan arus tabung dalam $\mathrm{mA}$, t merupakan waktu penyinaran dalam $\mathrm{s}$, $\mathrm{d}$ adalah jarak detektor ke objek dalam cm dan k merupakan faktor mesin pesawat sinar-X. Nilai k sangat berhubungan dengan faktor-faktor eksposi.

Pentingnya paparan radiasi sinar-X adalah untuk menghitung dosis serap. Dosis serap radiasi merupakan jumlah energi yang diserap oleh suatu medium yang dikenai radiasi per satuan massa medium tersebut. Dosis serap dirumuskan sebagai

$$
D=\frac{d E_{a b}}{d m}
$$

$$
\begin{aligned}
\text { dengan } \mathrm{D} & =\text { dosis serap } \\
\mathrm{dE}_{\mathrm{ab}} & =\text { energi yang diserap, dan } \\
\mathrm{dm} & =\text { massa medium }
\end{aligned}
$$




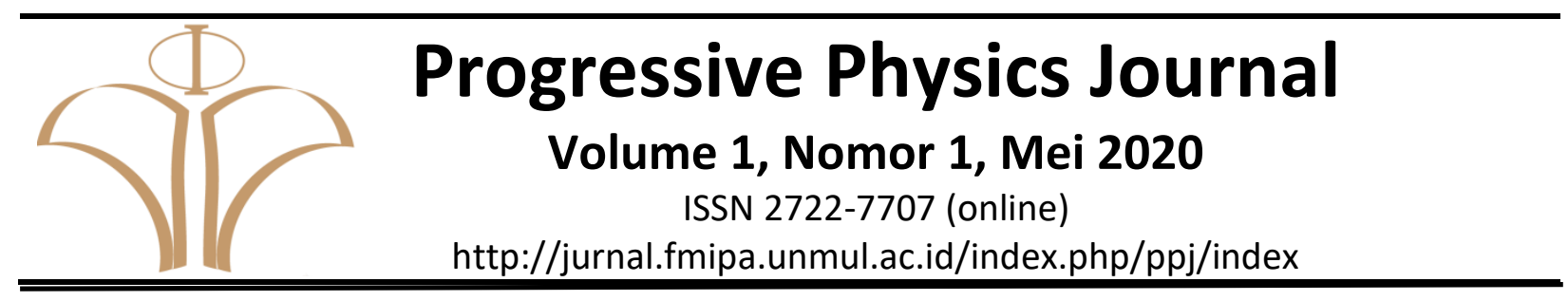

Untuk mendapatkan dosis serap radiasi terlebih dahulu harus menghitung paparan radiasi sinar- $\mathrm{X}$, setelah itu maka dapat dihitung nilai dosis serap radiasi dengan mengalikan dengan nilai konstanta $h$, yakni

$$
\mathrm{D}=h_{\text {udara }} \mathrm{E}
$$

$$
\begin{aligned}
\text { di mana } D & =\text { dosis serap, } \\
E= & \text { paparan, dan } \\
h_{\text {udara }}= & \text { faktor konversi dari } E \text { ke } D \\
& \text { (bergantung pada jenis medium dan energi foton). }
\end{aligned}
$$

Untuk medium udara, $\mathrm{h}=\mathrm{h}_{\text {udara }}=0,877 \frac{\mathrm{rad}}{R}=0,00877 \frac{\mathrm{Gy}}{R}$.

Paparan radiasi juga berkaitan dengan indeks paparan. Indeks paparan dalam digital radiografi telah digunakan untuk menunjukkan kecepatan relatif dan sensivitas reseptor digital untuk peristiwa sinar- $X$ dan idealnya untuk memberikan umpan balik bagi seorang radiografer. Namun setiap mesin pesawat sinar-X pabrikan tertentu memiliki parameter indeks paparan yang berbeda. Salah satunya yaitu pabrikan Fuji atau Shimadzu memiliki parameter S value dan memiliki symbol S, di mana meurut Seibert dan Morin [8].

$$
\frac{200}{S} \propto \mathrm{E}(m R)
$$

\begin{tabular}{|c|c|c|c|c|c|}
\hline No & Pabrikan & Parameter & $5 \mu \mathrm{Gy}$ & $\begin{array}{c}10 \\
\mu G y\end{array}$ & $\begin{array}{c}20 \\
\mu G y\end{array}$ \\
\hline 1 & $\begin{array}{l}\text { Canon } \\
\text { (brightness=16, } \\
\text { contrast=10) }\end{array}$ & REX & 50 & 100 & 200 \\
\hline 2 & $\operatorname{IDC}(S T=200)$ & F\# & -1 & 0 & 1 \\
\hline 3 & Philips & $\mathrm{El}$ & 200 & 100 & 50 \\
\hline 4 & Fuji & $S$ & 400 & 200 & 100 \\
\hline 5 & Konica & $S$ & 400 & 200 & 100 \\
\hline 6 & $\begin{array}{l}\text { Carestream } \\
\text { (CR, STD) }\end{array}$ & EI & 1700 & 2000 & 2300 \\
\hline
\end{tabular}

Lebih dari itu, Seibert dan Morin [8] mendapatkan nilai-nilai S untuk pesawat sinar-X merek Fuji atau Shimadzu yang telah terkalibrasi berdasarkan nilai-nilai dosis serap (tabel 1).

Tabel 1 Pabrikan dan parameter indeks paparan yang digunakan [8]

Halaman | 31 


7 Siemens $\quad$ El $\quad 500 \quad 1000 \quad 2000$

\section{METODE PENELITIAN}

Penelitian ini menggunakan tahap-tahap sebagai berikut:

Tahap pertama adalah mempelajari literatur yang akan digunakan sebagai kajian teori dalam penelitian, terutama yang berkaitan dengan sinar- $X$, pesawat sinar- $X$, faktor-faktor eksposi dan paparan radiasi. Kemudian pada tahap kedua melakukan identifikasi masalah.

Setelah itu tahap ketiga yaitu tahap pengambilan data mengenai faktor-faktor eksposi di instalasi radiologi RSUD Dr. Kanujoso Djatiwibowo Balikpapan sebanyak lima kali dengan tiga kali perulangan dimana jarak dari fokus ke detektor dan arus-waktu yang digunakan konstan yaitu $112,1 \mathrm{~cm}$ dan $100 \mathrm{mAs}$. sedangkan tegangan yang digunakan bervariasi yaitu dari $80 \mathrm{kV}, 85 \mathrm{kV}$, 90 kV, 95 kV dan 100 kV. Tahap keempat yaitu tahap analisis data dengan regresi linier berbobot.

\section{HASIL DAN PEMBAHASAN}

Untuk data-data mengenai tegangan $(\mathrm{kV})$, arus-waktu $(\mathrm{mAs})$, jarak $(\mathrm{cm})$ dan nilai S value diperlihatkan pada Tabel 2.

Tabel 2 Data pengukuran S value

\begin{tabular}{ccccccc} 
No & $\begin{array}{c}\mathrm{V} \\
(\mathrm{kV})\end{array}$ & $\begin{array}{c}\text { it } \\
(\mathrm{mAs})\end{array}$ & $\begin{array}{c}\mathrm{d} \\
(\mathrm{cm})\end{array}$ & $\mathrm{S}_{1}$ & $\mathrm{~S}_{2}$ & $\mathrm{~S}_{3}$ \\
\hline 1 & 80 & 100 & 112,1 & 126 & 124 & 126 \\
2 & 85 & 100 & 112,1 & 86 & 80 & 80 \\
3 & 90 & 100 & 112,1 & 57 & 65 & 68 \\
4 & 95 & 100 & 112,1 & 47 & 45 & 49 \\
5 & 100 & 100 & 112,1 & 40 & 41 & 40
\end{tabular}

Setelah didapat data S maka dihitung untuk rata-rata dan ketidakpastiannya dengan persamaan

$$
\overline{\mathrm{S}}=\frac{1}{3} \sum_{\mathrm{i}=1}^{3} \mathrm{~S}_{\mathrm{i}}
$$

dan

$$
\Delta \mathrm{S}=\sqrt{\frac{\sum_{\mathrm{i}=1}^{3}(\mathrm{~S}-\overline{\mathrm{S}})^{2}}{3(3-1)}}
$$

yang dikarenakan

$$
\mathrm{S}=\overline{\mathrm{S}} \pm \Delta \mathrm{S}
$$




\begin{tabular}{c} 
Progressive Physics Journal \\
Volume 1, Nomor 1, Mei 2020 \\
ISSN 2722-7707 (online) \\
http://jurnal.fmipa.unmul.ac.id/index.php/ppj/index \\
\hline \hline
\end{tabular}

Dan analisis perhitungannya diperlihatkan pada Tabel 3.

Tabel 3. Hasil Perhitungan rata-rata dan ketidakpastian nilai S

\begin{tabular}{ccccc}
\hline \multirow{2}{*}{ No } & $\mathrm{V}$ & it & $\mathrm{d}$ & $\mathrm{S}=\overline{\mathrm{S}} \pm \Delta \mathrm{S}$ \\
& $(\mathrm{kV})$ & $(\mathrm{mAs})$ & $(\mathrm{cm})$ & \\
\hline 1 & 80 & 100 & $112,10 \pm 0,05$ & $125,3 \pm 0,7$ \\
2 & 85 & 100 & $112,10 \pm 0,05$ & $82,0 \pm 2,0$ \\
3 & 90 & 100 & $112,10 \pm 0,05$ & $63,3 \pm 3,3$ \\
4 & 95 & 100 & $112,10 \pm 0,05$ & $47,0 \pm 1,2$ \\
5 & 100 & 100 & $112,10 \pm 0,05$ & $40,3 \pm 0,3$ \\
\hline
\end{tabular}

Kemudian ditarik titk-titik data hasil penelitian antara $\mathrm{V}$ versus $\mathrm{S}$ yang masing-masing diambil nilai rata-ratanya. Sebagaimana diperlihatkan pada Gambar 1.

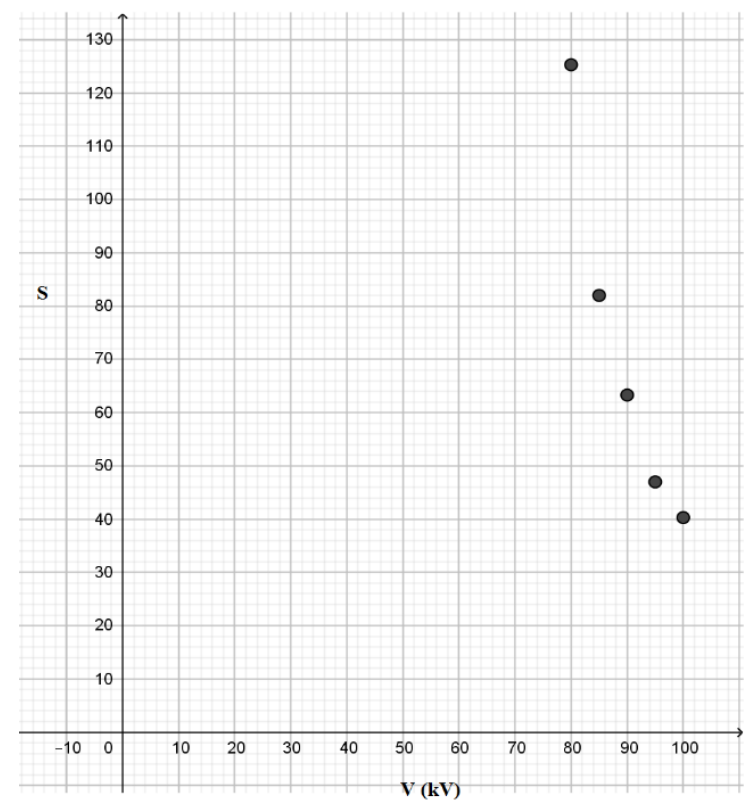

Gambar 1. Titik-titik data hasil penelitian antara tegangan (V) dan S

Setelah itu dilakukan analisis perhitungan regresi linier berbobot antara $\mathrm{V}^{2}$ dan $\mathrm{E}_{\mathrm{S}}$. Dimana nilai $E_{S}$ diperoleh dari persamaan

$$
E_{S}=\frac{200}{S}
$$


Oleh karena

$$
\mathrm{E}_{\mathrm{S}}=\overline{\mathrm{E}}_{\mathrm{S}} \pm \Delta \mathrm{E}_{\mathrm{S}}
$$

maka

$$
\overline{\mathrm{E}}_{\mathrm{S}}=\frac{200}{\overline{\mathrm{S}}}
$$

Dan

$$
\Delta \mathrm{E}_{\mathrm{S}}=\frac{200}{\overline{\mathrm{S}}^{2}}(\Delta \mathrm{S})
$$

Selanjutnya untuk kepentingan regresi linier berbobot menggunakan persamaan

$$
\mathrm{E}_{\mathrm{S}}=\mathrm{aV} \mathrm{V}^{2}+\mathrm{b}
$$

yang mana

$$
a=\bar{a} \pm \Delta a
$$

dan

$$
b=\bar{b} \pm \Delta b .
$$

Menurut Bevington (1969),

$$
\begin{gathered}
\bar{a}=\frac{\left(\sum_{i=1}^{5} \frac{1}{\left(\Delta E_{S}\right)_{i}^{2}}\right)\left(\sum_{i=1}^{5} \frac{V_{i}^{2} \bar{E}_{S i}}{\left(\Delta E_{S}\right)_{i}^{2}}\right)-\left(\sum_{i=1}^{5} \frac{V_{i}^{2}}{\left(\Delta E_{S}\right)_{i}^{2}}\right)\left(\sum_{i=1}^{5} \frac{\bar{E}_{S i}}{\left(\Delta E_{S}\right)_{i}^{2}}\right)}{\left(\sum_{i=1}^{5} \frac{1}{\left(\Delta E_{S}\right)_{i}^{2}}\right)\left(\sum_{i=1}^{5} \frac{V_{i}^{4}}{\left(\Delta E_{S}\right)_{i}^{2}}\right)-\left(\sum_{i=1}^{5} \frac{V_{i}^{2}}{\left(\Delta E_{S}\right)_{i}^{2}}\right)^{2}} \\
\Delta a=\sqrt{\frac{\sum_{i=1}^{5} \frac{1}{\left(\Delta E_{S}\right)_{i}^{2}}}{\left(\sum_{i=1}^{5} \frac{1}{\left(\Delta E_{S}\right)_{i}^{2}}\right)\left(\sum_{i=1}^{5} \frac{V_{i}^{4}}{\left(\Delta E_{S}\right)_{i}^{2}}\right)-\left(\sum_{i=1}^{5} \frac{V_{i}^{2}}{\left(\Delta E_{S}\right)_{i}^{2}}\right)^{2}}} \\
\bar{b}=\frac{\left(\sum_{i=1}^{5} \frac{\bar{E}_{S S}}{\left.\left(\Delta E_{S}\right)_{i}^{2}\right)}\right)\left(\sum_{i=1}^{5} \frac{V_{i}^{4}}{\left(\Delta E_{S}\right)_{i}^{2}}\right)-\left(\sum_{i=1}^{5} \frac{V_{i}^{2}}{\left(\Delta E_{S}\right)_{i}^{2}}\right)\left(\sum_{i=1}^{5} \frac{V_{i}^{2} \bar{E}_{S i}}{\left(\Delta E_{S}\right)_{i}^{2}}\right)}{\left(\sum_{i=1}^{5} \frac{1}{\left(\Delta E_{S}\right)_{i}^{2}}\right)\left(\sum_{i=1}^{5} \frac{V_{i}^{4}}{\left(\Delta E_{S}\right)_{i}^{2}}\right)-\left(\sum_{i=1}^{5} \frac{V_{i}^{2}}{\left(\Delta E_{S}\right)_{i}^{2}}\right)^{2}}
\end{gathered}
$$

dan

$$
\Delta \bar{b}=\sqrt{\frac{\sum_{i=1}^{5} \frac{V_{i}^{4}}{\left(\Delta E_{S}\right)^{2}}}{\left(\sum_{i=1}^{5} \frac{1}{\left(\Delta E_{S}\right)_{i}^{2}}\right)\left(\sum_{i=1}^{5} \frac{V_{i}^{4}}{\left(\Delta E_{S}\right)_{i}^{2}}\right)-\left(\sum_{i=1}^{5} \frac{V_{i}^{2}}{\left(\Delta E_{S}\right)_{i}^{2}}\right)^{2}}}
$$

Hasil yang diperoleh dari perhitungan yaitu

$E_{S}=(9,4909 \pm 0,1612) \times 10^{-4}\left(\frac{\mathrm{mR}}{\mathrm{kV}^{2}}\right) V^{2}+(-4,4727 \pm 0,1049) \mathrm{mR}$

dan dapat ditarik grafik linier antara $\mathrm{V}^{2}\left(\mathrm{kV}^{2}\right)$ dengan $\mathrm{E}_{\mathrm{S}}(\mathrm{mR})$ yang diperlihatkan pada Gambar 2 


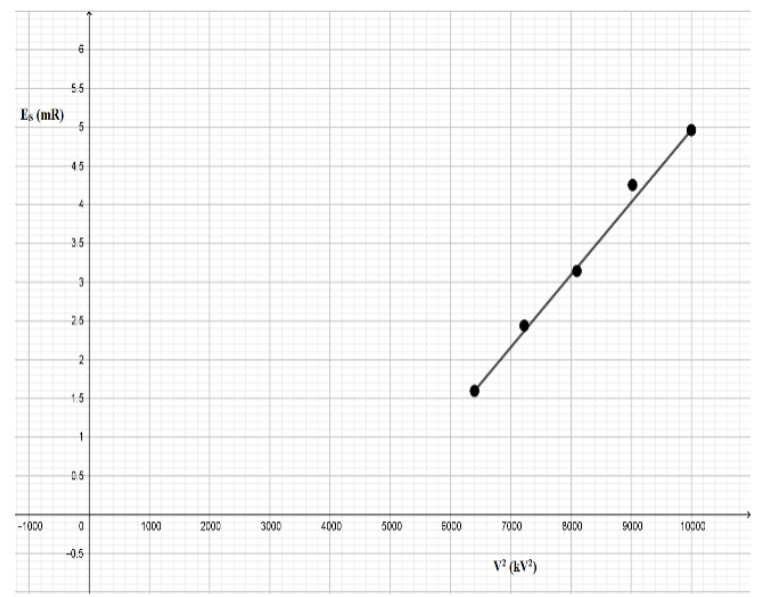

Gambar 2. Grafik kaitan antara $\mathrm{V}^{2}\left(\mathrm{kV}^{2}\right)$ dengan $\mathrm{E}_{\mathrm{S}}(\mathrm{mR})$

Sebelum mencari nilai faktor mesin pesawat sinar-X dilakukan analisis hubungan nilai $\mathrm{E}$ dan S yang terkalibrasi. Pada penelitian Seibert dan Morin (2011) mendapatkan bahwa pesawat sinar-X merek Fuji Shimadzu terkalibrasi memiliki nilai $S$ hasil pengukuran sebagaimana diperlihatkan pada tabel 4.5. Oleh karena itu nilai-nilai $S$ tersebut digunakan sebagai acuan pada penentuan nilai faktor mesin pesawat sinar-X merek Fuji Shimadzu terkalibrasi.

Tabel 3. Beberapa Nilai S Pada Pesawat Sinar-X Merek Fuji Shimadzu Terkalibrasi [8]

\begin{tabular}{ccccc}
\hline No & $\mathrm{D}(\mu \mathrm{Gy})$ & $\mathrm{E}(\mathrm{mR})$ & $\mathrm{S}$ & $\mathrm{E}_{\mathrm{SK}}(\mathrm{mR})$ \\
\hline 1 & 5 & 0,5701 & 400 & 0,5 \\
2 & 10 & 1,1403 & 200 & 1,0 \\
3 & 20 & 2,2805 & 100 & 2,0 \\
\hline
\end{tabular}

Berikut penjelasan tabel 4.5. Telah ditentukan nilai dosis serap (D) sebesar $5 \mu \mathrm{Gy}, 10 \mu \mathrm{Gy}$, dan $20 \mu$ Gy sehingga nilai paparan (E) dapat dihitung dengan rumus [1]:

$$
E=\frac{D}{h_{u \text { dara }}},
$$

di mana $\mathrm{h}_{\text {udara }}$ adalah nilai konstanta yaitu $\mathrm{h}_{\text {udara }}=0,00877 \mathrm{mGy}$. Oleh karena itu pada tabel 4.5 terdapat nilai E berturut-turut 0,5701 mR; 1,1403 mR dan 2,2805 mR. Berdasarkan nilai dosis serap tersebut kemudian diperoleh nilai $S$ berturut-turut 400, 200, dan 100, sehingga untuk mendapatkan nilai $E_{s k}$ yaitu dengan menggunakan persamaan (9) diperoleh nilai paparan sebesar 
$0,5 \mathrm{mR} ; 1,0 \mathrm{mR}$ dan $2,0 \mathrm{mR}$. Setelah itu diplot grafik antara $\mathrm{E}$ versus $\mathrm{Es}_{\mathrm{s}}$, hasilnya sebagaimana diperlihatkan pada gambar 4.3, yakni didapatkan persamaan garis:

$$
E_{S K}=0,8770 E
$$

yang mana $E$ dan $E_{S K}$ dalam satuan $m R$.

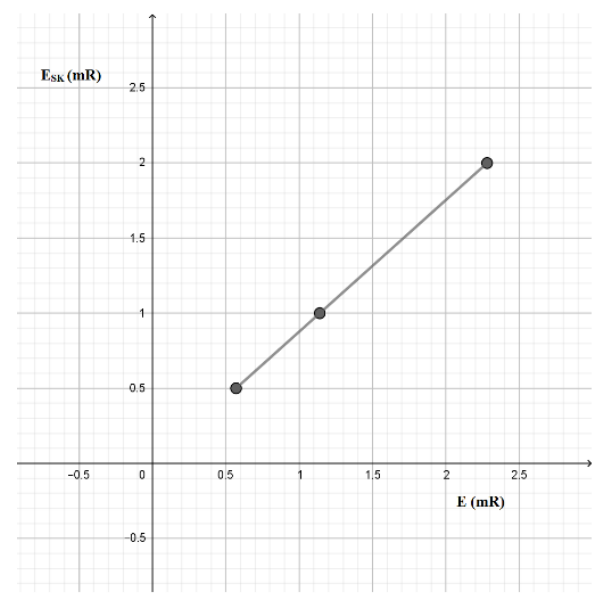

Gambar 3. Grafik hubungan antara E dengan $E_{S K}$

Pada penelitian ini dihitung nilai faktor mesin pesawat sinar- $X$ yang disimbolkan dengan k yakni sebagai berikut:

$$
k=\bar{k} \pm \Delta k
$$

sehingga

$$
k=\frac{a d^{2}}{\alpha i t} .
$$

Jadi

$$
\bar{k}=\frac{\bar{a} \bar{d}^{2}}{\alpha i t} .
$$

Kemudian untuk ketidakpastiannya adalah

$$
\Delta k=\frac{1}{\alpha i t} \sqrt{\bar{d}^{4}(\Delta a)^{2}+4 \bar{a}^{2} \bar{d}^{2}(\Delta d)^{2}}
$$

di mana nilai $\alpha=0,8770$

Oleh karena itu didapatkan nilai faktor mesin pesawat sinar-X nya adalah

$$
k=(0,1360 \pm 0,0124) \frac{\mathrm{mRcm}^{2}}{\mathrm{kV}^{2} \mathrm{mAs}}
$$

atau

$$
k=(0,3509 \pm 0,0320) \times 10^{-14} \frac{A^{2} S^{4}}{k g^{2}} .
$$

Nilai k dari hasil penelitian ini sebagaimana diperlihatkan oleh persamaan (22) adalah nilai faktor mesin pesawat sinar-X merek Shimadzu (Fuji) di Instalasi Radiologi RSUD Dr. Kanujoso 


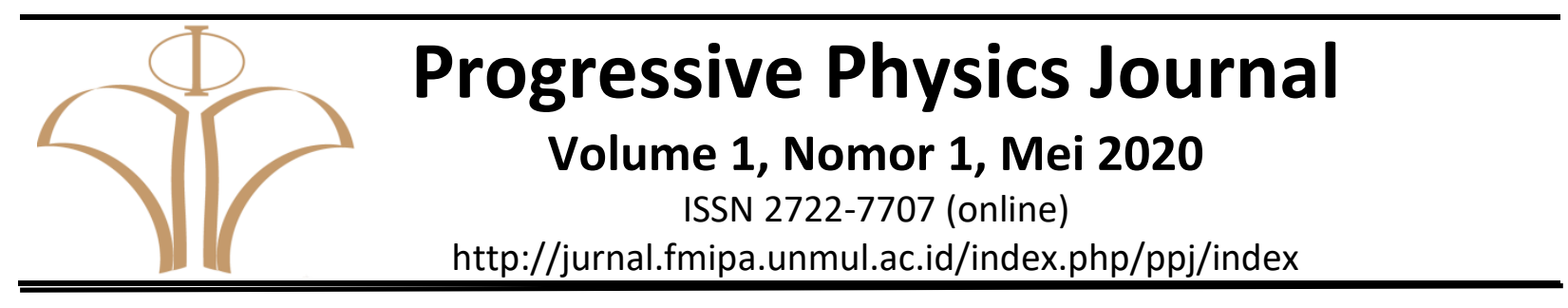

Djatiwibowo Balikpapan. Sebagai pembanding adalah hasil penelitian Ayad dkk (2001) untuk faktor mesin pesawat sinar-X merek Siemens yaitu berada pada rentang $5 \frac{\mathrm{mRcm}^{2}}{\mathrm{kV}^{2} \mathrm{mAs}}$ sampai dengan $30 \frac{\mathrm{mRcm}^{2}}{\mathrm{kV}^{2} \mathrm{mAs}}$ dan hasil penelitian dari Lestari (2018) untuk faktor mesin pesawat sinar-X merek Philip di Instalasi Radiologi RSUD Aji Muhammad Parikesit Tenggarong yakni $k=(0,128570 \pm$ $0,250972) \frac{\mathrm{mRcm}^{2}}{\mathrm{kV}^{2} \mathrm{mAs}}$.

Hasil penelitian ini juga mengkonfirmasi adanya persamaan

$$
\frac{200}{S}=a V^{2}+b
$$

sehingga

$$
S=\frac{200}{a V^{2}+b}
$$

dengan a dan b diperoleh dari proses regresi linier berbobot antara $V^{2}$ versus $\frac{200}{S}$. Oleh karena itu

$$
\bar{S}=\frac{200}{\bar{a} V^{2}+\bar{b}} .
$$

Apabila dinyatakan dalam bentuk grafik $\mathrm{V}$ versus $\bar{S}$ adalah sebagaimana diperlihatkan oleh grafik lengkung pada gambar 4, sedangkan titik-titik warna biru yang berdekatan dengan grafik lengkung tersebut diperoleh dari plot data-data penelitian. Nampak bahwa semua titik data penelitian menyentuh grafik lengkung. Hal ini memverifikasi kebenaran persamaan (25) untuk jangkauan pengukuran nilai $\mathrm{S}$ pada tegangan tabung pesawat sinar-X merek Shimadzu (Fuji) pada tegangan antara $80 \mathrm{kV}$ sampai dengan $100 \mathrm{kV}$.

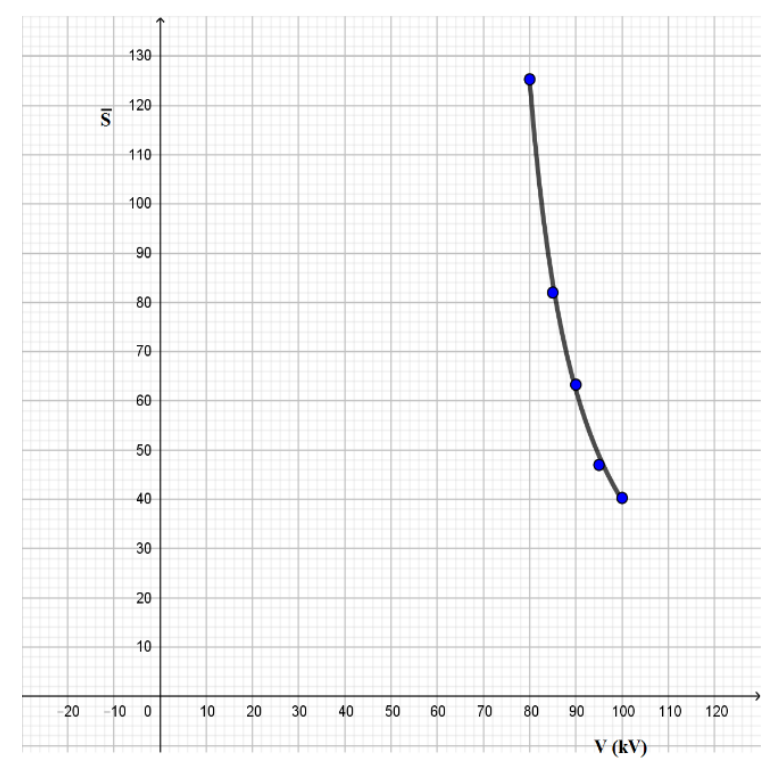


Gambar 4. Grafik antara V $(\mathrm{kV})$ dengan $\overline{\mathrm{S}}$

\section{KESIMPULAN}

Kesimpulan yang didapat pada penelitian ini adalah sebagai berikut:

1. Nilai faktor mesin pesawat sinar-X merek Shimadzu di RSUD Dr. Kanujoso Djatiwibowo Balikpapan data dipenuhi melalui:

a. Pengukuran nilai S pada variasi tegangan antara $80 \mathrm{kV}$ sampai dengan $100 \mathrm{kV}$

b. Analisis regresi linier berbobot antara $V^{2}$ dengan $\frac{200}{S}$ sehingga didapatkan persamaan

$$
\frac{200}{S}=a V^{2}+b
$$

dengan

$$
a=(9,4909 \pm 0,1612) \times 10^{-4} \frac{\mathrm{mR}}{\mathrm{kV}^{2}}
$$

dan

$$
b=(-4,4727 \pm 0,1049) \mathrm{mR}
$$

c. Menghitung nilai $k$ dengan menggunakan persamaan

$$
k=\frac{a d^{2}}{0,8770 i t}
$$

2. Dari penelitian ini diperoleh nilai faktor mesin pesawat sinar-X radiografi digital merek Shimadzu di Instalasi Radiologi RSUD Dr. Kanujoso Djatiwibowo Balikpapan yakni sebesar

$$
k=(0,1360 \pm 0,0124) \frac{m R c m^{2}}{k V^{2} m A s}
$$

atau

$$
k=(0,3509 \pm 0,0320) \times 10^{-14} \frac{A^{2} S^{4}}{k g^{2}}
$$

\section{UCAPAN TERIMA KASIH}

Penulis mengucapkan terima kasih kepada Laboratorium Fisika Dasar sebagai tempat peneliti melakukan analisis data, Jurusan Fisika Universitas Mulawarman sebagai tempat kegiatan peneliti menyelesaikan studinya dan RSUD Dr. Kanujoso Djatiwibowo Balikpapan yang telah memberikan bantuan dalam melakukan pengambilan data.

\section{DAFTAR PUSTAKA}

[1] Akhadi, M. 2000. Dasar-Dasar Proteksi Radiasi. Rineka Cipta. Jakarta.

[2] Ayad, M., Bakazi, A., dan Elharby, H. 2001. Dosimetry Measurements Of X-ray Machine Operating At Ordinary Radiology and Flouroscopic Examinations. Institute of Atomic Energy. Saudia Arabia. 


\title{
Progressive Physics Journal
}

\author{
Volume 1, Nomor 1, Mei 2020
}

ISSN 2722-7707 (online)

http://jurnal.fmipa.unmul.ac.id/index.php/ppj/index

[3] Bevington, Philip, dkk. 1969. Data Reduction and Error Analysis for the Physical Sciense. McGraw-Hill Education.

[4] Fahmi, A., Firdausi, S.,K., dan Budi, S., W. 2008. Pengaruh Faktor Eksposi Pada Pemeriksaan Abdomen Terhadap Kualitas Radiograf Dan Paparan Radiasi Menggunakan Computed Radiography. Laboratorium Fisika Atom dan Nuklir. Fisika FMIPA UNDIP.

[5] Lestari, J.,D. 2018. Kaitan Tegangan Tabung dan Indeks Paparan pada Pesawat Sinar-X Radiografi Digital Untuk Detektor Tanpa Grid dan dengan Grid. Fakultas Matematika dan Ilmu Pengetahuan Alam. Samarinda.

[6] Milvita, D., Yana, D., Nuraeni, N., dan Yuliati, H. 2009. Analisis Dosis Radiasi yang Diterima Mata, Tiroid dan Calvaria pada Pasien yang Menjalani Pemeriksaan CTScan Bagian Kepala. Prosiding Seminar Nasional Keselamatan Kesehatan dan Lingkungan V. Depok.

[7] Podgosrak, E.,B. 2005. Radiation Physics for Medical Physicists. McGill Universitas Health Centre Canada. Amerika.

[8] Seibert, J. Anthony., Morin, L. Richard. 2011. The Standardized Exposure Index For Digital Radiography : An Opportunity For Optimization Of Radiation Dose To The Pediatric Population. Pediatric Radiology. USA. DOI 10. 1007/s00247010-1954-6. 